\title{
Integrating a social norms perspective to address community violence against Sri Lankan women and girls: a call for research and practice
}

Whilst violence against women and girls (VAWG) by intimate partners has received increasing research attention in the last decade, non-partner violence in public spaces remains an underexplored area. With rapid urbanisation, violence against women and girls (VAWG) in public spaces, including on public transport, has become increasingly relevant. Global initiatives, such as UN Women's 'safe cities and safe public spaces' have begun unpacking harmful gender and social norms, which both excuse and legitimize violence and drive bystander inaction and survivor underreporting. However, there is a dearth of literature on the social norms that sustain VAWG in public spaces in South Asia, particularly in the Sri Lankan context. The following commentary will first make the case for a social norms approach to understanding and tackling VAWG in public spaces. Moving forward, alongside prevalence studies, we hope to see further normative research on VAWG in public spaces in Sri Lanka, which can inform programming and interventions that tackle the root causes of violence.

Keywords: Sexual violence; harassment; social norms; public spaces; Sri Lanka; public transport 


\section{COMMUNITY VIOLENCE AGAINST WOMEN IN SRI LANKA}

The statistic that 1 in 3 women worldwide has experienced some form of violence (sexual or physical) across their lifetime is widely known (García-Moreno et al., 2013). Violence against women and girls (VAWG) is rooted in unequal power relations between men and women is a grave violation of human rights, with harmful consequences for those who experience and witness it. VAWG negatively impacts directly or indirectly - on the reproductive, sexual, and mental health of women and girls (Heise, Ellsberg, \& Gottmoeller, 2002) as well as their participation in education, economic and civic life. For example, experiences of violence reduce women's freedom, formal labour participation and productivity (McIlwaine, 2013). As well as survivors, it also impacts society as a whole: children exposed to violence have poor education and employment outcomes, and are at greater risk of perpetrating and experiencing violence in the future (WHO/London School of Hygiene \& Tropical Medicine, 2010). A large proportion of sexual violence takes place in the home, between intimate partners, and has therefore been the focus of much research. However, VAWG transcends spaces and takes place in both the private and public sphere, as noted in the United Nations Declaration of the Elimination of Violence against Women, 1993 (UN General Assembly, 1993). Prevalence estimates of non-partner violence indicate worrying and unacceptable levels (Abrahams et al., 2014; García-Moreno et al., 2013). Research from India, Nepal and Bangladesh, indicates that over half of women have experienced violence by non-partners in public, and many experience it on a daily basis (ActionAid, 2015; Dhillon \& Bakaya, 2014; Neupane \& Chesney-Lind, 2013). Non-partner violence experienced in the public sphere has gained increasing attention (ActionAid, 2013, 2015; UN, 2017) corresponding with a global shift towards increasing levels of urbanisation (UN, 2014). Here, women and girls enter historically masculinised spaces to avail educational and economic opportunities, amongst other 


\section{COMMUNITY VIOLENCE AGAINST WOMEN IN SRI LANKA}

needs (Dunckel-Graglia, 2013; Mazumder \& Pokharel, 2018; Neupane \& ChesneyLind, 2013; Pain, 2016; Wilson \& Little, 2008). Women are at increased risk of exposure to VAWG because of their increased formal labour participation (women are increasingly seen in public spaces and traveling alone), which contradicts their gender roles and responsibilities 'homemakers' (Ruiz \& Garrido, 2018; Saha et al., 2018; Silvey, 2010). In urban settings, poor and marginalised women are at greater risk of violence on account of their poorer access to public services, such as safe transport, health and prevention (ActionAid, 2013). On the other hand, some literature indicates that gender roles become more 'relaxed' in urban settings, making VAWG less common (McIlwaine, 2015; Pozarny, 2016). Literature has shown that VAWG, wherever it takes place, is strongly governed by unequal power relations between men and women, while the underpinning social norms collectively justify violence and sustain a culture of fear and silence (Neupane \& Chesney-Lind, 2013; Otterbein, 1994; Sanday, 1981).

We propose that researchers look at the root causes of violence that women experience over the course of their lives, by embedding a social norms approach to understanding non-partner violence in the community. One useful conceptual framework is an adaptation of the ecological framework of behaviour change (B Cislaghi \& L Heise, 2018). The framework recognises that there is no single cause of violence, across time and place. It identifies four overlapping domains of influence (individual, material, institutional and social levels) and considers how social norms, power, and gender, intersect with each of these levels of influence to sustain violence. Social norms are the unwritten, informal understandings that govern the behaviour of members in a group (Bicchieri, 2012; Cialdini, Reno, \& Kallgren, 1990; Mackie \& Moneti, 2014). Norms dictate what is "typical" and "appropriate" behaviour, and play a key role in perpetuating violent behaviour (Ball Cooper \& Fletcher, 2012). Social norms 


\section{COMMUNITY VIOLENCE AGAINST WOMEN IN SRI LANKA}

can be descriptive (what most people do) or injunctive (what most people think others should do) (Mackie \& Moneti, 2014). Gender norms, a type of social norm, define what is expected of a man or a woman in a group or specific context. For example, they define a woman's role in society and delineate where she can go and what she can do. They include ideals of masculinity (e.g. that men must be 'strong', 'providers' and 'decision-makers') and femininity (e.g. that women must be 'submissive' and 'caretakers'). Gender norms can both create and reinforce unequal relationships, and power dynamics, between women and men (Cislaghi, Manji, \& Heise, 2018). They can shape beliefs around who should occupy a space and how and contribute in large measure to what Valentine (Valentine, 1989) described as "the spatial expression of patriarchy" (Valentine, 1989), or male dominance over public spaces, making women fearful of these spaces (Dunckel-Graglia, 2013; Mazumder \& Pokharel, 2018; Neupane \& Chesney-Lind, 2013; Pain, 2016; Wilson \& Little, 2008). Despite the important contribution of social norms in driving non-partner VAWG, there is a dearth of literature from the Sri Lankan context. The remainder of this commentary will focus on using a social and gender norms approach to understanding non-partner VAWG in public spaces. In particular, the focus is on public transport, as a place where violence is a common experience, and because its use is gendered (Dominguez Gonzalez, Arango, McCleary-Sills, \& Bianchi Alves, 2015; Levy, 2013; UN, 2017).

\section{[Figure 1]}

Sri Lanka lacks a systematic data collection mechanism for gender-based violence (GBV), including VAWG at the national level, and as a result disaggregated prevalence data does not exist. However, a number of research studies in Sri Lanka indicate that VAWG is widespread (García-Moreno et al., 2013; Gomez \& Gomez, 


\section{COMMUNITY VIOLENCE AGAINST WOMEN IN SRI LANKA}

2004; Jayasuriya-Illesinghe, 2011; WHO, 2013, 2018), though mirroring the global context, existing literature (Guruge, Jayasuriya-Illesinghe, Gunawardena, \& Perera, 2016; Jayasuriya, Wijewardena, \& Axemo, 2011) and policy focus has been on intimate partner violence (IPV) (Colombini et al., 2018). The arrest of a Sri Lankan woman in 2014, who slapped a man in response to sexual harassment (Wariyapola incident) and the brutal gang rape and murder of Sivaloganathan Vidhya, on her journey from school in 2015, are two prominent cases that garnered national and international attention for community VAWG in Sri Lanka. Further, the first national-level study on sexual harassment on public transport in Sri Lanka, carried out by the United Nations Population Fund (UNFPA), revealed that $90 \%$ of women and girls (15 - 35 years old) had been subjected to harassment at least once in their lifetime (UNFPA, 2015). Similarly, women who shared their accounts of violence on public buses through the Sri Lankan participatory journalism website Groundviews, described how pervasive and "normal" this experience was (Groundviews, 2016). A qualitative research study echoed these findings, showing that women frequently experienced sexual harassment on their journeys to work. These experiences negatively impacted on women's sense of empowerment, as can be seen in one woman's comment: "Men fiddle and touch us on buses. They do not think of us as people working for a living” (Hancock, 2017).

Research exploring the relationship between social norms and non-partner violence is limited in Sri Lanka. Nevertheless, some of the social and gender norms and underlying power dynamics, that help explain the prevalence of VAWG have been identified. A study carried out by the non-governmental organisation CARE, showed gender-inequitable attitudes amongst men and women (de Mel, Peiris, \& Gomez, 2013). Entrenched gender norms, for example, that a woman must 'take care of her home' and 'cook for her family' mean that women who 'defy' these norms (for example, by 


\section{COMMUNITY VIOLENCE AGAINST WOMEN IN SRI LANKA}

leaving the home to seek employment) are vulnerable to violence (de Mel et al., 2013; Herath, Guruge, Fernando, Jayarathna, \& Senarathna, 2018). Many Sri Lankan women agree that using violence to deal with problems is a sign of masculinity (Herath et al., 2018), while women as 'homemakers' and 'good wives' are expected to tolerate violence in order to maintain family unity and honour (de Mel et al., 2013). These norms create a culture of victim-blaming among communities, where women who experience violence are described as either 'promiscuous' or deserving of violence (de Mel et al., 2013). These norms are also reflected in the wider community, including among institutions and duty-bearers, whose responsibility it is to prevent and respond to violence. For example, despite the widespread prevalence of VAWG on public transport in Sri Lanka, only $4 \%$ of women and girls sought legal redress, fearing stigma and repercussions if they were to report it (UNFPA, 2015).

Norms intersect with different levels of influence, which can strengthen or weaken their impact on VAWG. For women in some urban areas of Sri Lanka, increased economic opportunities and participation in public life has increased their exposure to sexual exploitation and violence (Jordal, Wijewardena, Ohman, Essen, \& Olsson, 2015). Social and economic change brought about by the move to urban areas impacted on male and female ideas of masculinity. The resulting threat to men's power was a risk factor for their perpetration of violence (Jordal et al., 2015). Meanwhile, although over half (52\%) of survey respondents in Sri Lanka were aware of the law against sexual harassment, very few who experienced violence on public transport reported it to the police (UNFPA, 2015). This shows than an individual's awareness of an existing law is not enough to encourage reporting, if they anticipate negative social sanctions. 


\section{COMMUNITY VIOLENCE AGAINST WOMEN IN SRI LANKA}

The literature on what works to shift social norms at scale is nascent but expanding (Cislaghi \& Heise, 2016a, 2016b; Tankard \& Paluck, 2016). Cislaghi and Heise (2018) highlight how effective social norms interventions must look at multiple factors contributing to violence and how they intersect (Beniamino Cislaghi \& Lori Heise, 2018a, 2018b). They highlight the importance of making visible the changes in social norms that are occurring, to motivate a shift in behaviours amongst the wider community. Additionally, they recommend designing people-led interventions to embed strategies within the local context. An example such a community-led approach, is Tostan's Community Empowerment Programme (Tostan, 2018), which has proven successful in shifting harmful gender norms to address female genital cutting and child marriage across West Africa (Cislaghi, 2019). The Tostan model, allows individuals and communities to identify their own challenges, build their own vision and develop solutions to these. This is supported by selected community members who have been trained to support and facilitate discussion throughout the programme. One component encourages dialogue around rights and health, an entry point for more difficult discussions around norms and violence, while the other teaches practical skills to bring about change (e.g. project management). All of this takes place over a number of years, allowing time for social norms to change. Importantly, gender inequality and power imbalances are addressed, as women and girls make up half of participants and are encouraged to take on leadership roles. One community-based norms intervention in rural Sri Lanka, has also shown that facilitating dialogue around family health, relationships, and gender norms, can shift women's acceptance of partner violence (Herath et al., 2018). Such approaches, modified for the Sri Lankan and urban context, may be relevant to shifting norms related to VAWG in public spaces. 


\section{COMMUNITY VIOLENCE AGAINST WOMEN IN SRI LANKA}

There are, however, challenges to transforming social and gender norms. For example, community interventions that include an awareness-raising component, as is often the case, need detailed knowledge of the norms at play, including whether they are descriptive or injunctive, to ensure that messaging does not 'backfire' (Cialdini, 2003). For example, saying that many people engage in a harmful behavior (such as sexual harassment), may increase acceptance of the behaviour. In addition, gender norms assign power to certain community members (for example, men), which they may or may not wish to uphold. Groups wishing to maintain the norms that keep their power in place may be resistant to change and is why engaging the community as a whole, women, men, girls, and boys, is essential to designing social norms interventions (Jewkes, Flood, \& Lang, 2015).

In conclusion, Sri Lankan women are at risk of violence and harassment, within and outside of their homes. Social and gender norms are a key entry point for interventions to prevent violence, especially as some of the social and gender norms that sustain violence in the home, also support violence against women and girls in public spaces. Literature from other South Asian countries, in addition to the limited IPV literature from Sri Lanka, has been useful in indicating social and gender norms that sustain VAWG. However, we urge further research into the social and gender norms sustaining violence against women in public spaces in the Sri Lankan context. Future research by the authors of this commentary will explore the individual, material, and institutional factors that sustain violence in the community, and on public transport, and how these intersect with power and social and gender norms. This will be used to inform effective holistic intervention design and best practice. 


\section{References}

Abrahams, N., Devries, K., Watts, C., Pallitto, C., Petzold, M., Shamu, S., \& GarcíaMoreno, C. (2014). Worldwide prevalence of non-partner sexual violence: a systematic review. The Lancet, 383(9929), 1648-1654. doi:10.1016/s01406736(13)62243-6

ActionAid. (2013). Women and The City II: Combating violence against women and girls in urban public spaces - the role of public services. Retrieved from

ActionAid. (2015). Women and the City III: A summary of baseline data on violence against women and girls in seven countries. Retrieved from

Ball Cooper, L., \& Fletcher, E. (2012). Reducing Societal Discrimination against Adolescent Girls Using Social Norms to Promote Behavior Change. Retrieved from London:

Bicchieri, C. (2012). Norms, Conventions, and the Powever of Expectations. In N. Cartwright \& E. Montuschi (Eds.), Philosophy of Social Science. New York Oxford University Press.

Cialdini, R. B. (2003). Crafting Normative Messages to Protect the Environment. Current Directions in Psychological Science, 12(4).

Cialdini, R. B., Reno, R. R., \& Kallgren, C. A. (1990). A focus theory of normative conduct: Recycling the concept of norms to reduce littering in public places. Journal of Personality and Social Psychology, 58(6), 1015-1026.

Cislaghi, B. (2019). The potential of a community-led approach to change harmful gender norms in low- and middle-income countries. Retrieved from

Cislaghi, B., \& Heise, L. (2016a). Measuring Gender-related Social Norms, Learning Report 1. Retrieved from

Cislaghi, B., \& Heise, L. (2016b). Measuring Gender-related Social Norms: Report of a Meeting, Baltimore Maryland, June 14-15, 2016. Retrieved from http://researchonline.lshtm.ac.uk/4646972/1/Baltimore norms meeting report_GREEN VoR.pdf

Cislaghi, B., \& Heise, L. (2018a). Theory and practice of social norms interventions: eight common pitfalls. Global Health, 14(1), 83. doi:10.1186/s12992-018-0398$\mathrm{X}$

Cislaghi, B., \& Heise, L. (2018). Using social norms theory for health promotion in low-income countries. Health Promot Int.

Cislaghi, B., \& Heise, L. (2018b). Using social norms theory for health promotion in low-income countries. Health Promotion International.

Cislaghi, B., Manji, K., \& Heise, L. (2018). Social Norms and Gender-related Harmful Practices, Learning Report 2, Theory in suport of better practice. Learning Group on Social Norms and Gender-related Harmful Practices. Retrieved from

Colombini, M., Mayhew, S. H., Lund, R., Singh, N., Swahnberg, K., Infanti, J., . . . Wijewardene, K. (2018). Factors shaping political priorities for violence against women-mitigation policies in Sri Lanka. BMC Int Health Hum Rights, 18(1), 22. doi:10.1186/s12914-018-0161-7

de Mel, N., Peiris, P., \& Gomez, S. (2013). Broadening Gender: Why Masculinities Matter. Retrieved from Colombo:

Dhillon, M., \& Bakaya, S. (2014). Street Harassment: A Qualitative Study

of the Experiences of Young Women in

Delhi. SAGE Open, 4(3). doi:10.1177/2158244014543786

Dominguez Gonzalez, K., Arango, D. J., McCleary-Sills, J., \& Bianchi Alves, B. (2015). Violence Against Women and Girls (VAWG) Resource Guide: 


\section{COMMUNITY VIOLENCE AGAINST WOMEN IN SRI LANKA}

Transport Brief Retrieved from http://www.vawgresourceguide.org/sites/vawg/files/briefs/vawg_resource_guide transport brief formattedv3.pdf

Dunckel-Graglia, A. (2013). "Pink transportation" in Mexico City: reclaiming urban space through collective action against gender-based violence. Gender \& Development, 21(2), 265-276.

García-Moreno, C., Pallitto, C., Devries, K., Stöckl, H., Watts, C., \& Abrahams, N. (2013). Global and regional estimates of violence against women: Prevalence and health effects of intimate partner violence and non-partner sexual violence. In.

Gomez, S., \& Gomez, M. (2004). Sri Lanka: The Law's Response to Women Victims of Violence. In S. Goonesekere (Ed.), Violence, Law and Women's Rights in South Asia: Sage Publications.

Groundviews (Producer). (2016, December 2018). Mapping Street Harasment This Women's Day Retrieved from https://groundviews.org/2016/03/08/mappingstreet-harassment-this-womens-day/

Guruge, S., Jayasuriya-Illesinghe, V., Gunawardena, N., \& Perera, J. (2016). Intimate partner violence in Sri Lanka: a scoping review. Ceylon Medical Journal, 60(4), $133-138$.

Hancock, P. (2017). Violence, Women, Work and Empowerment: Narratives from Factory Women in Sri Lanka's Export Processing Zones. Gender, Technology and Development, 10(2), 211-228. doi:10.1177/097185240601000203

Heise, L., Ellsberg, M., \& Gottmoeller, M. (2002). A global overview of gender-based violence. International Journal of Gynecology and Obstetrics, 78.

Herath, T., Guruge, D., Fernando, M., Jayarathna, S., \& Senarathna, L. (2018). The effect of a community based health promotion intervention to change gender norms among women in a rural community in Sri Lanka. BMC Public Health, 18(1), 977.

Jayasuriya, V., Wijewardena, K., \& Axemo, P. (2011). Intimate partner violence against women in the capital province of Sri Lanka: prevalence, risk factors, and help seeking. Violence Against Women, 17(8), 1086-1102.

Jayasuriya-Illesinghe, V. (2011). Review of Research Evidence on Gender Based Violence $(G B V)$ in Sri Lanka (2nd ed.). Colombo: Sri Lanka Medica Association.

Jewkes, R., Flood, M., \& Lang, J. (2015). From work with men and boys to changes of social norms and reduction of inequities in gender relations: a conceptual shift in prevention of violence against women and girls. The Lancet, 385, 1580-1589.

Jordal, M., Wijewardena, K., Ohman, A., Essen, B., \& Olsson, P. (2015). 'Disrespectful men, disrespectable women': men's perceptions on heterosexual relationships and premarital sex in a Sri Lankan Free Trade Zone - a qualitative interview study. BMC Int Health Hum Rights, 15(3). Retrieved from https://www.ncbi.nlm.nih.gov/pubmed/25889367

Levy, C. (2013). Travel choice reframed: "deep distribution" and gender in urban transport. Environment and Urbanization, 25(1), 47-63. doi:10.1177/0956247813477810

Mackie, G., \& Moneti, F. (2014). What are Social Norms? How are they Measured? In E. Denny \& H. Shakya (Eds.): UNICEF/UCSD Center on Global Justice Project Cooperation Agreement. 
Mazumder, H., \& Pokharel, B. (2018). Sexual Violence on Public Transportation: A Threat to Women's Mobility in Bangladesh. Journal of Aggression, Maltreatment \& Trauma, 1 - 3 .

Mcllwaine, C. (2013). Urbanization and gender-based violence: exploring the paradoxes in the global South Environment and Urbanization, 25(1), 65 - 79

McIlwaine, C. (2015). Gender-based violence and assets in just cities: triggers and transformation. In C. Moser (Ed.), Gender, Asset Accumulation and Just Cities: Pathways to transformation (1st ed., pp. 220). London: Routledge.

Neupane, G., \& Chesney-Lind, M. (2013). Violence against women on public transport in Nepal: sexual harassment and the spatial expression of male privilege. International Journal of Comparative and Applied Criminal Justice, 38(1), 2338.

Otterbein, K. (1994). A cross-cultural study of rape. In O. K (Ed.), Feuding and Warfare (pp. 119 - 132): Gordon and Beach Science Publishers.

Pain, R. (2016). Space, sexual violence and social control: integrating geographical and feminist analyses of women's fear of crime. Progress in Human Geography, 15(4), 415-431. doi:10.1177/030913259101500403

Pozarny, P. (2016). Gender roles and opportunities for women in urban environments. Retrieved from Birmingham, UK:

Ruiz, D., \& Garrido, A. (2018). Breaking the Mould: Changing Belief Systemss and Gender Norms to Eliminate Violence Against Women in Latin America and the Caribbean. Retrieved from

Saha, P., Van Veen, S., Davies, I., Hossain, K., van Moorten, R., \& van Mellaert, L. (2018). Paid work: the magic solution for young women to achieve empowerment? Evidence from the Empower Youth for Work project in Bangladesh. Gender \& Development, 26(3), 551-568.

Sanday, P. R. (1981). The socio-cultural context of rape: A cross-cultural study. Journal of Social Issues, 37(4), 5 - 27.

Silvey, R. M. (2010). Stigmatized Spaces: Gender and Mobility under crisis in South Sulawesi, Indonesia. Gender, Place \& Culture, 7(2), 143-161. doi:10.1080/713668869

Tankard, M. E., \& Paluck, E. L. (2016). Norm perception as vehicle for social change. Soc Issues Policy Rev, 10(1), 181 - 211.

Tostan. (2018). Generational change in three years: an ambitious campaign to empower millions in

West Africa. Retrieved from https://www.tostan.org/programs/communityempowerment-program/

UN. (2014). World Urbanization Prospects: The 2014 Revision, Highlights. Retrieved from New York:

UN. (2017). Safe Cities and Safe Public Spaces Global Results Report. Retrieved from http://www.unwomen.org/-

/media/headquarters/attachments/sections/library/publications/2017/safe-citiesand-safe-public-spaces-global-results-report-en.pdf?la=en\&vs=45:

UN General Assembly. (1993). Declaration on the Elimination of Violence Against Women.

UNFPA. (2015). Sexual Harassment on Public Trains and Buses United Nations Population Fund.

Valentine, G. (1989). The Geography of Women's Fear. Area, 21(4), 385-390. 


\section{COMMUNITY VIOLENCE AGAINST WOMEN IN SRI LANKA}

WHO. (2013). Global and regional estimates of violence against women: prevalence and health effects of intimate partner violence and nonpartner sexual violence. Retrieved from

WHO. (2018). Country Profile on Gender-Based Violence in Sri Lanka.

WHO/London School of Hygiene \& Tropical Medicine. (2010). Preventing intimate partner and sexual violence against women: taking action and generating evidence. Retrieved from Geneva:

Wilson, E., \& Little, D. E. (2008). The Solo Female Travel Experience: Exploring the 'Geography of Women”s Fear'. Current Issues in Tourism, 11(2), 167-186. 